ARTICLE

\title{
Dichloromethylation of enones by carbon nitride photocatalysis
}

\author{
Stefano Mazzanti (1) 1,3, Bogdan Kurpil ${ }^{1,3}$, Bartholomäus Pieber (i) ${ }^{2}$, Markus Antonietti (i) ${ }^{1}$ \& \\ Aleksandr Savateev (iD ${ }^{1 \times}$
}

Small organic radicals are ubiquitous intermediates in photocatalysis and are used in organic synthesis to install functional groups and to tune electronic properties and pharmacokinetic parameters of the final molecule. Development of new methods to generate small organic radicals with added functionality can further extend the utility of photocatalysis for synthetic needs. Herein, we present a method to generate dichloromethyl radicals from chloroform using a heterogeneous potassium poly(heptazine imide) (K-PHI) photocatalyst under visible light irradiation for C1-extension of the enone backbone. The method is applied on 15 enones, with $\gamma, \gamma$-dichloroketones yields of $18-89 \%$. Due to negative zeta-potential $(-40 \mathrm{mV})$ and small particle size $(100 \mathrm{~nm}) \mathrm{K}-\mathrm{PHI}$ suspension is used in quasi-homogeneous flow-photoreactor increasing the productivity by 19 times compared to the batch approach. The resulting $\gamma, \gamma$-dichloroketones, are used as bifunctional building blocks to access valueadded organic compounds such as substituted furans and pyrroles.

\footnotetext{
${ }^{1}$ Department of Colloid Chemistry, Max Planck Institute of Colloids and Interfaces, Am Mühlenberg 1, 14476 Potsdam, Germany. ${ }^{2}$ Department of Biomolecular Systems, Max Planck Institute of Colloids and Interfaces, Am Mühlenberg 1, 14476 Potsdam, Germany. ${ }^{3}$ These authors contributed equally:

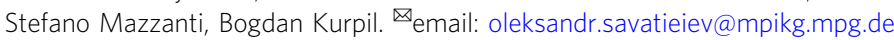


C arbon nitrides (CNs) are "all-in-one" photocatalysts that mediate dozens of different photocatalytic reactions and enable bifunctionalization of (hetero)arenes in one pot ${ }^{1}$. The organic semiconductors have also been efficiently employed in a continuous flow system for chemical synthesis eliminating the last obstacle (poor light penetration in heterogeneous solidliquid mixture) on the way to widespread applications in organic synthesis ${ }^{2}$. Because of their low cost, ease of synthesis and stability against reactive intermediates and photobleaching, CNs already play an important role as heterogeneous photocatalysts for organic transformations ${ }^{3-5}$. CNs are also very versatile, and can be tailored depending on the application by bandgap engineering at the atomic and molecular level ${ }^{6,7}$.

Most photocatalytic reactions are based on single electron transfer between the reagents and the photocatalyst ${ }^{8}$. Therefore, reactive open shell species are ubiquitous intermediates in photocatalytic processes ${ }^{9-11}$. Small organic radicals, such as $\mathrm{CH}_{3}$, $\mathrm{CF}_{3}, \mathrm{CHF}_{2}{ }^{1}$, and perfluoroalky ${ }^{12}, \mathrm{CH}_{3} \mathrm{O}^{13}$ etc. are used for the functionalization of the organic molecules in order to tune steric and electronic properties. Furthermore, the lipophilicity and metabolic stability of pharmaceuticals may be adjusted in this way ${ }^{14,15}$. Despite their importance for medicinal chemistry, $\mathrm{CF}_{3}$, alkyl, and $\mathrm{CH}_{3} \mathrm{O}$ groups are chemically stable. Therefore, further diversification of the molecule at these newly formed sites is problematic. For example, cleavage of $\mathrm{C}-\mathrm{F}$ bond in $\mathrm{CF}_{3}$-group is extremely demanding ${ }^{16}$. The same applies to $\mathrm{C}-\mathrm{O}$ bond in the $\mathrm{CH}_{3} \mathrm{O}$-group ${ }^{17,18}$.

Conversely $\mathrm{CHCl}_{2}$ radical from the pool of small organic radicals is synthetically more useful. It enables the installation of an electrophilic carbon, and the $\mathrm{C}-\mathrm{Cl}$ bonds can be conveniently cleaved using weak nucleophiles. In other words, the $\mathrm{CHCl}_{2}$ radical allows for $\mathrm{C}_{1}$-extension of the substrate framework, while simultaneously adding a chemically active functionality ${ }^{19}$. From this point of view, the $\mathrm{CHCl}_{2}$ radical can be regarded as a "small functional radical".

Despite the obvious synthetic utility of the dichloromethyl radical, literature is still lacking reactions using dichloromethyl moieties in conjugate additions-the kind of reaction resembling a traditional polar Michael addition. The latter was well studied in photoredox catalysis ${ }^{20-23}$. An example shown in Fig. 1a employs methyl groups in tertiary amines and $\mathrm{C}=\mathrm{C}$ double bond as coupling partners. The chemistry of dichloromethyl radicals is restricted to a few examples, while such radicals are generated predominantly by catalyst containing rare precious metals or dangerous chemicals (Fig. 1b, c). Our alternative approach uses cheap heterogenous carbon nitride $(\mathrm{CN})$ photocatalysts (1-10 Euro per gram on a gram-scale synthesis $)^{24}$ and have a low toxicity ${ }^{25}$.

We hypothesized that chloroform can be used as atom efficient source of $\mathrm{CHCl}_{2}$ radicals. Although chloroform readily gives dichlorocarbene in the presence of strong bases, we concede that photocatalyst will alter the path of chloroform decomposition. Formation of the dichloromethyl radical thereby may be achieved by one-electron reduction of chloroform followed by elimination of a chloride anion.

In order to trigger this process, we chose potassium poly (heptazine imide) (K-PHI), a member of the CN family ${ }^{26}$. Upon irradiation with visible light, metastable long-lived radicals are generated that have been used as a pool of electrons to reduce different substrates ${ }^{27}$. Earlier, we developed photocatalytic methods to synthesize thioamides ${ }^{28}$, dibenzyl sulfanes ${ }^{29}, 1,3,4$ oxadiazoles $^{3}, \mathrm{~N}$-fused pyrroles $^{30}$, cyclopentanes ${ }^{27}$, and halogenated aromatic hydrocarbons using $\mathrm{K}-\mathrm{PHI}^{31}$. In related works, the long-lived carbon nitride radicals were applied in the delayed evolution of hydrogen ${ }^{32,33}$.

Due to the advantages of flow reactors ${ }^{34,35}$, several types of such photoreactors employing carbon nitrides have been reported a Photocatalyzed conjugated addition to enones

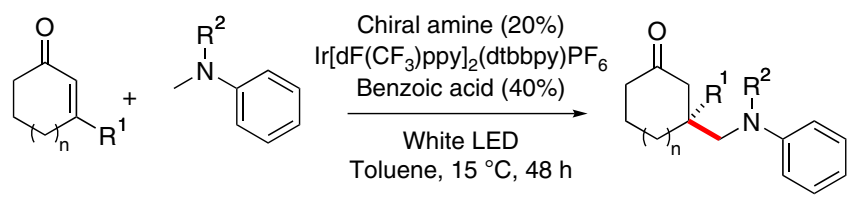

b Cyclisation of trichloroacetamides<smiles>COC1=CCC(N(Cc2ccccc2)C(=O)C(F)(Cl)Cl)CC1</smiles>

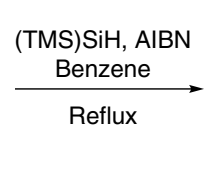<smiles>C=C1C(=O)N(Cc2ccccc2)C2CCC(=O)C1C2</smiles>

C Preparation of dichlorinated oxindoles
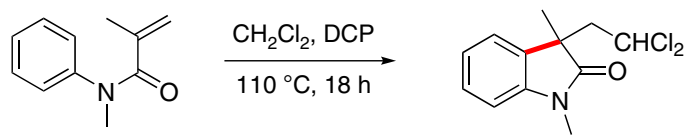

d This work - Dichloromethyl radical addition to enones
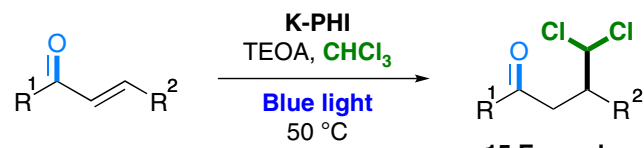

15 Examples

$15-89 \%$ Yield

Fig. 1 Previous works related to the designed reaction are presented.

a Conjugate addition to enones. b Cyclisation of trichloroacetamides. c Synthesis of dichlorinated oxindoles. d Photocatalytic reaction developed in this work.

- packed bed photoreactor $^{36}$, serial micro batch photoreactors ${ }^{2}$, and triphasic flow photoreactor ${ }^{37}$. Due to relatively small particle size (average diameter $100 \mathrm{~nm}$ ) and highly negative zeta-potential $(-40 \mathrm{mV})^{38}, \mathrm{~K}-\mathrm{PHI}$ gives stable colloidal solution and has been used in quasi-homogeneous catalysis ${ }^{39}$. Due to these features colloidal solution of K-PHI can be used in simple plug-flow photoreactors that are designed for homogeneous reaction mixtures.

All in all, we present an unusual photocatalyzed radical addition of dichloromethyl radicals to enones to form a new C-C bond (Fig. 1d). In this approach chloroform is used as a source of dichloromethyl radicals. The reaction is catalyzed by K-PHI using blue light irradiation. Using the discovered reaction, we show that light scattering by semiconductor particulate strongly affects their performance in batch reactors limiting the scalability of such transformations. A nineteen times higher productivity is achieved using a dedicated flow photoreactor employing quasihomogeneous K-PHI nanoparticles. Finally, dichloromethyl adducts, i.e., $\gamma, \gamma$-dichloroketones, are used to access bifunctional building blocks and several classes of heterocyclic compounds.

\section{Results}

Optimization of reaction conditions. Along these arguments, we studied the designed reaction between chalcone 1a, chloroform, tetrahydroisoquinoline (THIQ) as an electron donor and K-PHI as the photocatalyst (see SI for preparation and characterization of K-PHI, Supplementary Fig. 1). Dichloroketone 2a was synthesized initially with $17 \%$ yield when 1 equivalent of THIQ was used (Table 1, entry 1). By increasing the amount of THIQ gradually to four equivalents, the yield of 2 a was increased to $51 \%$ (entry 3 ). However, even higher yield (62\%) of $\mathbf{2 a}$ was achieved by 
Table 1 Screening of reaction conditions.

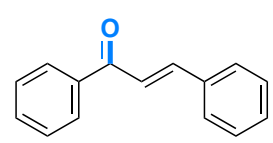

$1 a$

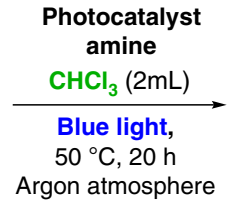

Argon atmosphere

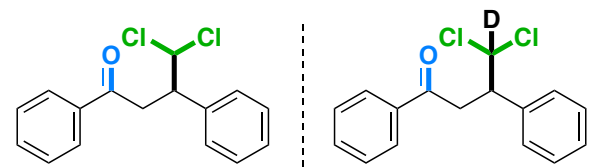

$2 a-d_{1}$

\begin{tabular}{|c|c|c|c|}
\hline Entry & Amine & Photocatalyst & Yield (\%) \\
\hline 1 & THIQ (1 eq, $0.05 \mathrm{mmol}$ ) & $\mathrm{K}-\mathrm{PHI}(5 \mathrm{mg})$ & 17 \\
\hline 2 & THIQ (2 eq., $0.1 \mathrm{mmol}$ ) & $\mathrm{K}-\mathrm{PHI}(5 \mathrm{mg})$ & 33 \\
\hline 3 & THIQ (4 eq., 0.2 mmol) & $\mathrm{K}-\mathrm{PHI}(5 \mathrm{mg})$ & 51 \\
\hline 4 & TEOA (3 eq., $0.15 \mathrm{mmol}$ ) & $\mathrm{K}-\mathrm{PHI}(5 \mathrm{mg})$ & 62 \\
\hline 5 & TEOA (10 eq., $0.5 \mathrm{mmol}$ ) & $\mathrm{K}-\mathrm{PHI}(5 \mathrm{mg})$ & 97 \\
\hline 6 & TEOA (10 eq., $0.5 \mathrm{mmol}$ ) & - & - \\
\hline $7^{b}$ & TEOA (10 eq., $0.5 \mathrm{mmol}$ ) & $\mathrm{K}-\mathrm{PHI}(5 \mathrm{mg})$ & - \\
\hline 8 & - & $\mathrm{K}-\mathrm{PHI}(5 \mathrm{mg})$ & - \\
\hline $9^{c}$ & TEOA (10 eq., $0.5 \mathrm{mmol}$ ) & K-PHI (5 mg) & 99 \\
\hline 10 & TEOA (10 eq., $0.5 \mathrm{mmol}$ ) & $\mathrm{Na}-\mathrm{PHI}(5 \mathrm{mg})$ & 49 \\
\hline 11 & TEOA (10 eq., $0.5 \mathrm{mmol}$ ) & mpg-CN (5 mg) & 85 \\
\hline 12 & TEOA (10 eq., $0.5 \mathrm{mmol})$ & $\mathrm{CdS}(20 \% \mathrm{~mol})$ & 70 \\
\hline $13^{d}$ & TEOA (10 eq., $0.5 \mathrm{mmol}$ ) & $\mathrm{TiO}_{2}(20 \% \mathrm{~mol})$ & 94 \\
\hline 14 & TEOA (10 eq., $0.5 \mathrm{mmol}$ ) & $\operatorname{lr}(p p y)_{3}(2.5 \% \mathrm{~mol})$ & 97 \\
\hline 15 & TEOA (10 eq., $0.5 \mathrm{mmol}$ ) & {$\left[\mathrm{Ru}(\mathrm{bpy})_{3}\right] \mathrm{Cl}_{2}(2.5 \% \mathrm{~mol})$} & 8 \\
\hline
\end{tabular}

Reaction conditions: 1 eq., $0.05 \mathrm{mmol}, 10.4 \mathrm{mg}$ of 1a; under light irradiation $\left(\lambda=461 \mathrm{~nm}, 51 \pm 0.03 \mathrm{~mW} \mathrm{~cm}{ }^{-2}\right)$, blue LED.

aYields estimated by GC-MS.

bNo light.

CReaction performed in $\mathrm{CDCl}_{3}$

Reaction performed under UV light $\left(\lambda=365 \mathrm{~nm}, 17.5 \pm 0.03 \mathrm{~mW} \mathrm{~cm}^{-2}\right)$.

using 3 equivalents of triethanolamine (TEOA) as electron donor (entry 4). The optimum conditions include ten equivalents of TEOA, under which we achieved $97 \%$ yield (entry 5 ). The reaction does not proceed without catalyst, light or a sacrificial electron donor (entry 6-8). $\mathrm{CDCl}_{3}$ is a suitable source of $\mathrm{CDCl}_{2}$ radicals offering a route for $d$-labeled dichloroketones $2 \mathbf{a}$ - $d_{1}$ with $99 \%$ yield (entry 9). We also evaluated the robustness of the reaction using different alcohols as hole scavengers, observing the formation of the desired product in all cases, albeit in lower yield (Table S1, entry 11-14). These results illustrate the better ability of amines to donate electrons compared to alcohols, due to lower oxidation potentials (e.g., $+0.5 \mathrm{~V}$ for TEOA, $+1.5 \mathrm{~V}$ for benzyl alcohol and $+1.9 \mathrm{~V}$ for $\mathrm{MeOH}$, EtOH, ${ }^{i} \mathrm{PrOH}$ (Supplementary Note 1). It is also supported by higher $\mathrm{H}_{2}$ production rate over carbon nitride materials using TEOA as electron donor compared to $\mathrm{MeOH}$ and $\mathrm{EtOH}^{40,41}$ and comparative tests of benzyl alcohol oxidation versus benzylamine ${ }^{37,42}$. Moderate heating $\left(50^{\circ} \mathrm{C}\right)$ facilitates the reaction, as the yield of $\mathbf{2 a}$ was $64 \%$ when reaction was performed at $20^{\circ} \mathrm{C}$ (Supplementary Table 1, entry 21). We also compared the catalytic activity of other materials and photoredox complexes. Na-PHI gave 2 a with $49 \%$ yield (entry 10$)^{43}$. Similar behavior was already observed during the photocatalytic synthesis of thioamides ${ }^{28}$. Mesoporous graphitic carbon nitride (mpg-CN) gave 2a with comparable yield $85 \%$ (entry 11 ). The inorganic semiconductors $\mathrm{CdS}$ and $\mathrm{TiO}_{2}$ gave $2 \mathbf{a}$ in 70 and $94 \%$ yield, respectively (entries 12,13). Homogeneous $\operatorname{Ir}(\mathrm{ppy})_{3}$ gave 2a with $97 \%$ yield (entry 14 ), while $\left[\mathrm{Ru}(\mathrm{bpy})_{3}\right] \mathrm{Cl}_{2}$ only resulted in $8 \%$ of $2 \mathrm{a}$ (entry 15). Furthermore, it was also shown that recycled K-PHI remains photocatalytically active for at least two further cycles (Supplementary Table 2).

Reaction scope. Using the optimized conditions fifteen dichloroketones have been isolated with $18-89 \%$ yield (Figs. $2 \mathrm{a}-\mathrm{o}$ ). The characterization of products was conducted by NMR analysis. Dichloroketones 2 do not give stable molecular ions in the mass spectra (electron ionization). For example, the expected $m / z$ value for $2 \mathbf{a}$ is 292. However, a signal with $\mathrm{m} / z 221$ was detected (Supplementary Fig. 2). The latter corresponds to 2,4-diphenylfuran. In general 2,4-diarylsubstituted furans are products of oxygen nucleophilic attack at $\mathrm{CHCl}_{2}$-group followed by elimination of two molecules $\mathrm{HCl}$ under the conditions of GC-MS data acquisition. Below we employ the reactivity of $\mathrm{CHCl}_{2}$ group in synthesis of pyrroles and furans. Nonetheless, elemental analysis of $\mathbf{2 a}$ revealed chlorine content in excellent agreement with the calculated content confirming the proposed structure. We further proved the product structure, using deuterated chloroform as dichloromethyl source, observing the rise of the triplet in the ${ }^{13} \mathrm{C}$ NMR spectrum in the $d$-labeled compound $\left(\mathbf{2 a}-\boldsymbol{d}_{\mathbf{1}}\right)$.

Dichloromethylated chalcones bearing strong electron withdrawing groups, i.e., $\mathrm{CN}-, \mathrm{MeO}_{2} \mathrm{C}-$, and pyridin-2-yl, $\mathbf{1 p}-\mathbf{r}$, gave the corresponding products $\mathbf{2 p - r}$ in low yields as analyzed by ${ }^{1} \mathrm{H}$ NMR spectrometry of the crude reaction mixture (Supplementary Note 2). Nevertheless, we envision toolbox of synthetic organic chemistry to be useful for further diversification of the products structures employing, for example, methyl-group in $\mathbf{2 b}, \mathbf{F}$-atoms in $\mathbf{2 d}, \mathbf{e}, \mathbf{h}$ and intrinsically reactive sites in $\mathbf{2} \mathbf{i}, \mathbf{j}$. Common reactive Michael acceptors, such as methyl vinyl ketone and acrylonitrile, gave only trace amounts of $\mathrm{CHCl}_{2}$ addition to the double bond as evidenced by GC-MS (Supplementary Note 3). Even more reactive Michael acceptors, i.e., methacrolein, methyl acrylate, and 2-furanone, gave a complex mixture and the desired products could not be identified (Supplementary Note 4).

Analysis of the substrates scope suggests that diarylsubstituted enones in general are more suitable substrates for photocatalytic dichloromethylation than terminal alkenes. Nevertheless, the advantages of the developed method are a simpler protocol and safer conditions. For example, the synthesis of $\mathbf{2 a}$ and $\mathbf{2 l}$ was 
<smiles>O=C(CC(c1ccccc1)C(Cl)Cl)c1ccccc1</smiles>

2a $88 \%$<smiles>O=C(CC(c1ccc(C(F)(F)F)cc1)C(Cl)Cl)c1ccccc1</smiles>

2f $85 \%$<smiles>Cc1ccc(C(CC(=O)c2ccccc2)C(Cl)Cl)cc1</smiles>

2b $89 \%$<smiles>O=C(CC(c1cccc(C(F)(F)F)c1)C(Cl)Cl)c1ccccc1</smiles>

$2 g 82 \%$<smiles>O=C1CCCC(C(Cl)Cl)C1</smiles>

2I

K-PHI $\quad$ 2k $65 \%$ mpg-CN $27 \%^{a}$ $\operatorname{Ir}(\mathrm{ppy})_{3} \quad 17 \%^{\mathrm{a}}$<smiles>CC(=O)CC(c1ccccc1)C(Cl)Cl</smiles>

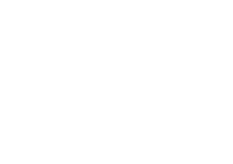

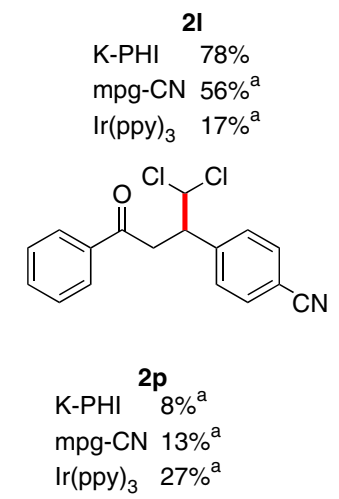<smiles>O=C(CC(c1ccc(F)c(F)c1)C(Cl)Cl)c1ccccc1</smiles>

2h $70 \%$<smiles>COc1ccc(C(CC(=O)c2ccccc2)C(Cl)Cl)cc1</smiles>

2c $83 \%$<smiles>O=C(CC(c1ccc(F)cc1)C(Cl)Cl)c1ccccc1</smiles>

2d $84 \%$<smiles>O=C(CC(c1cccs1)C(Cl)Cl)c1ccccc1</smiles>

2i K-PHI 54\% mpg-CN $10 \%^{\mathrm{a}}$ $\operatorname{Ir}(\mathrm{ppy})_{3} \quad 7 \%^{\mathrm{c}}$<smiles>O=C(CC(c1ccc(Cl)cc1)C(Cl)Cl)c1ccccc1</smiles>

$2 \mathrm{~m} 27 \%\left(31 \%^{\mathrm{a}}\right)$<smiles>CC(=O)c1ccc(C(CC(=O)c2ccccc2)C(Cl)Cl)cc1</smiles>

2q $19 \%^{\mathrm{a}}$

$$
\begin{array}{ll}
\multicolumn{2}{c}{\mathbf{2 n}} \\
\text { K-PHI } 20 \%\left(26 \%{ }^{\mathrm{a}}\right) \\
\text { mpg-CN } 15 \%^{\mathrm{a}} \\
\text { Ir }(\mathrm{ppy})_{3} \quad 29 \%^{\mathrm{a}}
\end{array}
$$<smiles>O=C(CC(c1ccccn1)C(Cl)Cl)c1ccccc1</smiles>

2 r $9 \%^{a}$<smiles>O=C(CC(c1cccc(F)c1)C(Cl)Cl)c1ccccc1</smiles>

2e $80 \%$<smiles>O=C(CC(c1ccco1)C(Cl)Cl)c1ccccc1</smiles>

$$
\begin{array}{ll}
\text { K-PHI } & \multicolumn{2}{c}{\mathbf{j}} \\
\text { mpg-CN } & 1 \%^{\mathrm{a}} \\
\text { Ir(ppy) } & 34 \%^{\mathrm{a}}
\end{array}
$$<smiles>O=C(CC(c1cccc(I)c1)C(Cl)Cl)c1ccccc1</smiles>

$2018 \%\left(26 \%{ }^{a}\right)$

mpg-CN $13 \%^{a}$
$\operatorname{Ir}(\text { ppy })_{3} \quad 27 \%^{a}$

Fig. 2 Scope of enone substrates. Reaction conditions: enone 1 ( 1 eq., $0.05 \mathrm{mmol}$ ); TEOA (10 eq., $0.5 \mathrm{mmol}, 67 \mu \mathrm{L}) ; \mathrm{CHCl}_{3}(2 \mathrm{~mL}) ; \mathrm{Argon}$ atmosphere; under light irradiation ( $\lambda=461 \mathrm{~nm}, 51 \pm 0.03 \mathrm{~mW} \mathrm{~cm}^{-2}$, blue LED), isolated yields. Superscript "a" indicates the yields determined by ${ }^{1} \mathrm{H}$ NMR using $1,2,3-$ trimethoxybenzene as internal standard.

described earlier using exotic reagents such as dichloromethyllithium $^{44}$. A comparison of K-PHI, mpg-CN, and $\operatorname{Ir}(\mathrm{ppy})_{3}$ photocatalysts using selected enones, $\mathbf{1} \mathbf{i}-\mathbf{l}, \mathbf{n}$, p, revealed that $\mathrm{K}$ PHI in general gives the products in higher yields.

In the course of studying suitable reagents to install $\mathrm{C}_{\mathrm{x}} \mathrm{Hal}_{\mathrm{y}} \mathrm{H}_{\mathrm{z}}-$ groups in the enone 1a, we tested other halogenated reagents, including dichloromethane, bromoform, iodoform, 1,1,2,2-tetrachloroethane and tetrachloromethane (Supplementary Table 1). Careful analysis of the reaction mixture revealed that addition of $\mathrm{CHBr}_{2}$-groups, $\mathrm{CHI}_{2}$-groups, and $\mathrm{C}_{2} \mathrm{HCl}_{4}$-groups to enone 1a indeed took place. However, the products are not stable and undergo further chemical transformations, such as HX elimination and subsequent cyclizations to 2,4-diphenylfuran (in case of bromoform and iodoform) or dichlorodihydropyranes (in case of tetrachloroethane) (Supplementary Note 5). Compared to bromoform and iodoform, chloroform is beneficial due to higher selectivity in the reaction of enones $\mathrm{C} 1$ backbone extension.

Scaling the dichloromethylation reaction of 1a in batch led to gradual decrease of the dichloroketone yield, from $88 \%$ (on 0.05 mmol scale) to $23 \%$ (on $5 \mathrm{mmol} \mathrm{scale)} \mathrm{(Supplementary} \mathrm{Table} \mathrm{3).}$ After careful investigation, we concluded that the origin for such drastic drop of the product 2a yield is poor light penetration in the depth of the batch reactor due to light scattering by suspended semiconductor particles (Supplementary Note 6) ${ }^{45}$.
Quasi-homogeneous flow photoreactor. In order to overcome limitations of the batch approach, we performed the reaction in a continuous flow reactor made out of thin (inner diameter 1.6 $\mathrm{mm}$ ) fluorinated ethylene propylene (FEP) tubing (Fig. 3). The use of carbon nitrides has been reported in serial micro-batch reactors ${ }^{2}$, that use gas-liquid segments to avoid clogging. A simplified system is applicable for K-PHI due to relatively small particle diameter $(100 \mathrm{~nm})$ and negative zeta-potential $(\zeta)$ (Fig. 3a). Electrostatic stabilization allows pumping colloidal solution (Fig. 3b and Supplementary Note 7) without using a gasliquid system (Fig. 3c). Using flow approach, 2a was obtained with $57 \%$ yield. Considering convenience of K-PHI suspension pumping through thin FEP tubing along with easiness of the photocatalyst recovery, the entire system enables quasihomogeneous photocatalysis in flow ${ }^{39}$.

As seen from the light intensity measurements (Fig. 3d-f), the FEP tubing filled with the reaction mixture absorbs $74 \%$ $\left[\left(I_{0}-I_{\mathrm{T} 2}\right) / I_{\mathrm{T} 0}\right]$ of light. These results suggest that by performing the reaction in flow, more homogeneous irradiation of K-PHI particulate is achieved compared to the reaction in batch (Supplementary Note 6). Furthermore, we solved the proble$\mathrm{m}$ of poor light permeability through a semiconductor suspension and increased the productivity of $\gamma, \gamma$-dichloroketone 2a synthesis by a factor of 19 . 

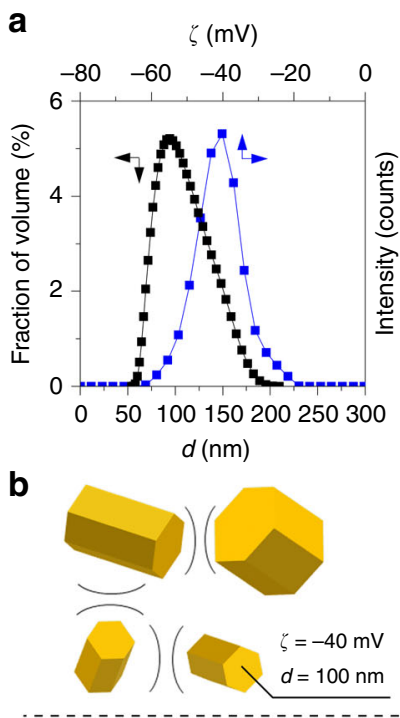

C TEOA

Enone 1a

Pump 1

$\mathrm{CHCl}_{3}$ :DMSO (6:4) $\quad 8.0 \mathrm{~mL} \mathrm{~h}^{-1}$
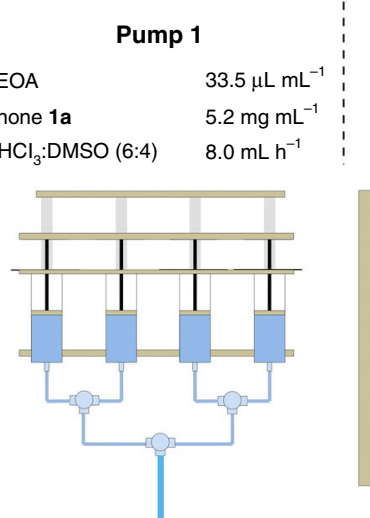

\begin{tabular}{lr}
\multicolumn{2}{c}{ Pump 2 } \\
$\begin{array}{lr}\text { K-PHI } & 10 \mathrm{mg} \mathrm{mL}^{-1} \\
\text { Flow } & 2.0 \mathrm{~mL} \mathrm{~h}^{-1}\end{array}$
\end{tabular}

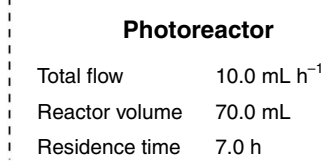

d
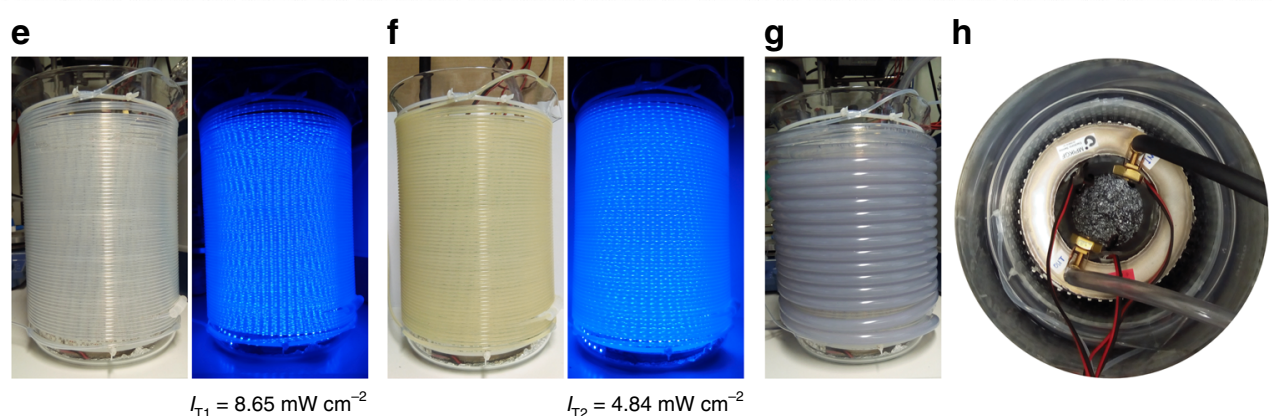

Fig. 3 K-PHI colloidal solution properties and flow photoreactor design used in this work. a Zeta-potential $(\zeta)$ and hydrodynamic diameter (d) of K-PHI particles suspended in water. Source data are provided as a Source Data file. b Schematic representation of colloidal solution stabilization by electrostatic repulsion. c Schematic representation of the reactor setup and reaction parameters. Yield was determined by GC-MS collecting the solution for 30 min from the photoreactor; comparison between flow and batch are made considering the optimized reaction conditions in batch. $\mathbf{d}$ The light source was built by wrapping self-adhesive LED stripes around a hollow steel cylinder shell equipped with inlet and outlet for water-cooling. Incident light intensity ( $I_{0}$ ) measured at zero distance from the light source $18.5 \mathrm{~mW} \mathrm{~cm}^{-2}$. e Light source placed inside a glass beaker wrapped with FEP tubing under day light and blue light source. Transmitted light intensity $\left(I_{T 1}\right)$ was measured at zero distance from the FEP tubing. $\mathbf{f} F E P$ tubing filled with a reaction mixture under day light and blue light source. Transmitted light intensity $\left(I_{\mathrm{T} 2}\right)$ was measured at zero distance from the FEP tubing. $\mathbf{g}$ Photoreactor wrapped with PVC tubing to maintain the desired temperature during the experiment. $\mathbf{h}$ View from the top on the assembled flow photoreactor immersed into a glass beaker. The space between the beakers is filled with cooling agent (water).

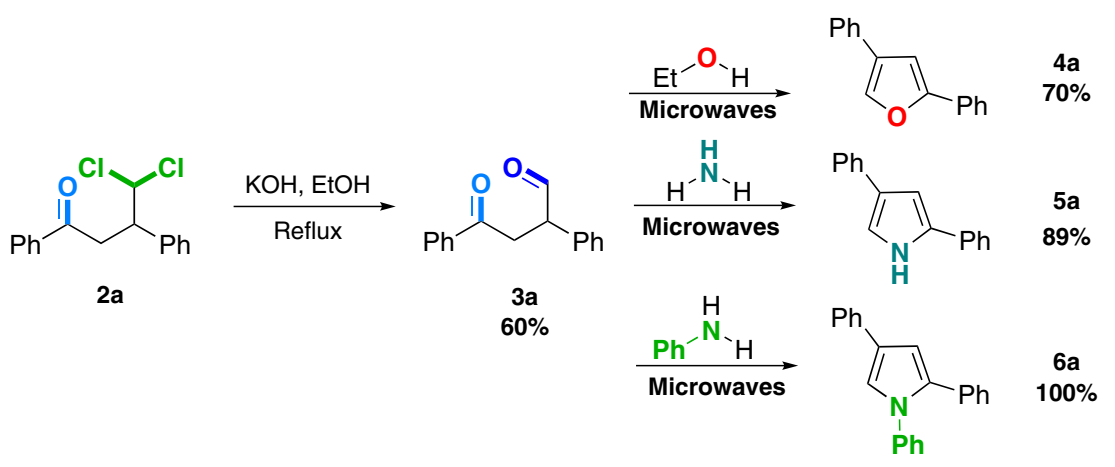

Fig. 4 Preparation of different heterocyclic bioactive compounds from enones. Isolated yields are shown.

Application of $\gamma, \gamma$-dichloroketones in organic synthesis. Finally, the $\gamma, \gamma$-dichloroketones obtained by the photocatalytic generation and addition of dichloromethyl radicals to enones were used to install other reactive functional groups. As a practical example, dichloroketone $\mathbf{2 a}$ was converted to $\beta$-formyl ketone $3 \mathbf{a}$ by simple hydrolysis with $60 \%$ yield (Fig. 4 ). The ketoaldehyde $3 \mathbf{a}$ was then transformed into multi-substituted heterocycles (4a-6a) using microwave assisted condensations with a series of nucleophiles. For instance, furan and pyrrole scaffolds have been used in synthesis of bioactive substances ${ }^{46,47}$.

Mechanism. To support the role of chloroform as electron acceptor, we developed a method for oxidative coupling of 
benzylamines (Fig. 5) ${ }^{48}$. As example, we synthesized four imines with $83-100 \%$ yield. These results offer an alternative route for such transformations using chloroform as a solvent and electron acceptor (Supplementary Fig. 3 for detailed mechanism of amines coupling).

The proposed mechanism of the reported photocatalytic reaction is shown in Fig. 6 . In the first step, K-PHI is excited by blue photons giving excited state of the photocatalyst (K-PHI*). Removal of an electron from TEOA by K-PHI* (reductive quenching of the photocatalyst), leads to the formation of the long-lived radical anion $\mathrm{K}-\mathrm{PHI}{ }^{\bullet}$, that has the typical deep green color $^{27,29}$. Chloroform is subsequently oxidized by a single electron transfer event, forming the chloroform radical anion that eliminates a chloride anion resulting in a dichloromethyl radical. Addition of the dichloromethyl radical to the $\beta$-carbon atom of the enone gives intermediate $\mathbf{i}-\mathbf{1}$. Abstraction of hydrogen from TEOA leads to the desired product 2 . While TEOA acts as hole scavenger, chloroform simultaneously acts as solvent and electron acceptor to complete the photocatalytic cycle, as it was already proposed by Chen et al. ${ }^{49}$ It is also possible to detect traces of different chlorinated compounds, that result from side radical reactions of the dichloromethyl radical, via GC-MS. By running experiments in the absence of the enone, we observed the formation of halogenated compounds including tetrachloroethane that is likely formed via a homocoupling of dichloromethyl radicals (Supplementary Table 4; Supplementary Figs. 4, 5, 6).

\section{Discussion}

In this work, we extended the library of small organic radicals available for photocatalytic synthesis to dichloromethyl radicals than can be conveniently generated from chloroform. The
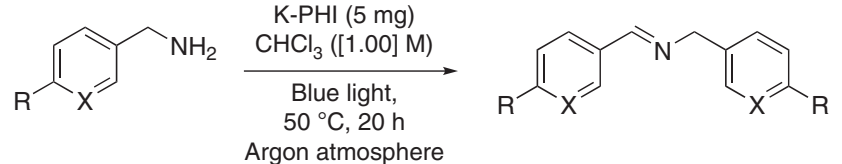

$$
\begin{aligned}
& \text { 1'c: } R=\mathrm{H}, X=\mathrm{CH} \\
& \text { 1'd: } \mathrm{R}=\mathrm{Me}, \mathrm{X}=\mathrm{CH} \\
& \text { 1'e: } \mathrm{R}=\mathrm{OMe}, \mathrm{X}=\mathrm{CH} \\
& \text { 1'f: } \mathrm{R}=\mathrm{H}, \mathrm{X}=\mathrm{N}
\end{aligned}
$$

$$
\begin{aligned}
& \text { 2'c: } R=H, X=C H \\
& \text { 2'd: } R=M e, X=C H \\
& \text { 2'e: } R=O M e, X=C H \\
& \text { 2'f: } R=H, X=N
\end{aligned}
$$

method was validated in a 1,4 addition of dichloromethyl radicals to enones. The process is photocatalyzed by the heterogeneous, metal free carbon nitride photocatalyst K-PHI. Fifteen $\gamma, \gamma$ dichloroketones were isolated in moderate to excellent yield. The possibility to use other polyhalogenated compounds such as bromoform, iodoform and 1,1,2,2-tetrachloroethane has been demonstrated. Light scattering by carbon nitride particles has been identified as limiting factor for scaling these transformations. The results suggest that, in a typical photocatalytic experiment using $2.5 \mathrm{mg} \mathrm{mL}^{-1}$ of semiconductor particles, the penetration depth of light is only $3 \mathrm{~mm}$. In polar solvent, such as DMSO, nanoparticles of K-PHI give stable suspension that was pumped through a thin $(1.6 \mathrm{~mm}$ internal diameter $)$ tubing. $\gamma, \gamma$ dichloroketone $\mathbf{2 a}$ has been also synthesized using quasihomogeneous photoreactor. The $\gamma, \gamma$-dichloroketones obtained in this work were proved to be useful building blocks with applications in the synthesis of bifunctional compounds that can be used for the preparation of heterocyclic bioactive molecules. The use of chloroform as solvent and electron acceptor was also demonstrated in the oxidative coupling of benzylamines.

\section{Methods}

Microwave reactions. Experiments were carried out in a CEM Discover ${ }^{\circledR}$ SP System microwave reactor.

Compounds characteriation. ${ }^{1} \mathrm{H}$ and ${ }^{13} \mathrm{C}$ NMR spectra were recorded on Agilent $400 \mathrm{MHz}$ (at $400 \mathrm{MHz}$ for Protons and $101 \mathrm{MHz}$ for Carbon-13). Chemical shifts are reported in ppm versus solvent residual peak: chloroform- $d 7.26 \mathrm{ppm}$ ( ${ }^{1} \mathrm{H}$ NMR), $77.1 \mathrm{ppm}\left({ }^{13} \mathrm{C} \mathrm{NMR}\right)$; acetonitrile- $d_{3} 1.94 \mathrm{ppm}\left({ }^{1} \mathrm{H} \mathrm{NMR}\right), 118.3 \mathrm{ppm}$ $\left({ }^{13} \mathrm{C}\right.$ NMR $)$.

Mass spectral data were obtained using Agilent GC 6890 gas chromatograph, equipped with HP-5MS column (inner diameter $=0.25 \mathrm{~mm}$, length $=30 \mathrm{~m}$, and film $=0.25 \mu \mathrm{m}$ ), coupled with Agilent MSD 5975 mass spectrometer (electron ionization).

Electrochemistry. Cyclic voltammetry $(\mathrm{CV})$ measurements were performed in a glass single-compartment electrochemical cell. Glassy carbon (diameter $3 \mathrm{~mm}$ ) was used as a working electrode (WE), $\mathrm{Ag}$ wire in $\mathrm{AgNO}_{3}(0.01 \mathrm{M})$ with tetrabutylammonium perchlorate $(0.1 \mathrm{M})$ in $\mathrm{MeCN}$ as a reference electrode $(\mathrm{RE}), \mathrm{Pt}$ wire as a counter electrode. Each compound was studied in a $50 \mathrm{mM}$ concentration in a $0.1 \mathrm{M}$ tetrabutylammonium perchlorate (TBAP)/chloroform electrolyte solution $(10 \mathrm{~mL})$. Before voltammograms were recorded, the solution was purged with Ar, and an Ar flow was kept in the headspace volume of the electrochemical cell during CV measurements. A potential scan rate of $0.050 \mathrm{~V} \mathrm{~s}^{-1}$ was chosen, and the potential window ranging from $+2.5 \mathrm{~V}$ to $-2.5 \mathrm{~V}$ (and backwards) was investigated. Cyclic voltammetry was performed under room-temperature conditions $\left(\sim 20-22^{\circ} \mathrm{C}\right)$.

Fig. 5 Oxidative coupling of benzylamines. GC-MS yields are shown.

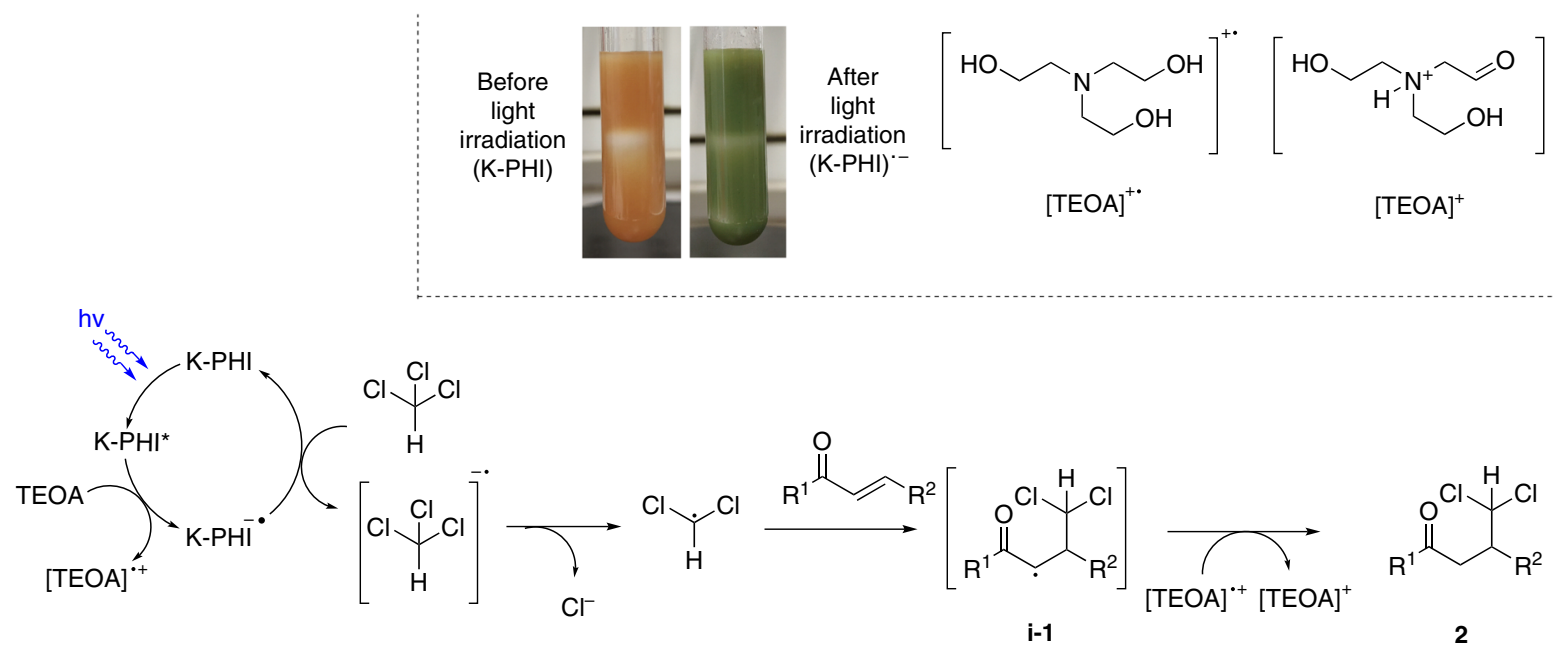

Fig. 6 Proposed mechanism of the generation of dichloromethyl radicals and their addition to enones. Inset shows images of the reaction mixture before and after light irradiation and structures of TEOA oxidation products. 
Photocatalysts characterization. Zeta-potentials were measured in aqueous colloidal solution of K-PHI using a Malvern Zetasizer instrument.

Hydrodynamic diameter of K-PHI particles in water was measured using Malvern Zetasizer instrument.

General method for dichloro-ketone preparation (2a-I). A glass tube with rubber-lined cap was evacuated and filled with argon three times. To this tube triethanolamine $(74.6 \mathrm{mg}, 66 \mu \mathrm{L}, 0.5 \mathrm{mmol})$, corresponding chalcone $(50 \mu \mathrm{mol}), \mathrm{K}$ PHI $(5 \mathrm{mg})$ and chloroform $(2 \mathrm{~mL})$ were added. Resulting mixture was stirred at $50{ }^{\circ} \mathrm{C}$ under irradiation of Blue LED $(\lambda=461 \mathrm{~nm})$ for $20 \mathrm{~h}$. Then reaction mixture was cooled to room temperature and centrifuged, clear solution was separated and solid residue was washed with chloroform $(2 \mathrm{~mL})$ and centrifuged again. Organic solutions were combined and evaporated to dryness. Residue after evaporation was purified by silica gel column chromatography using mixture of hexane/diethyl ether (98:2) as an eluent.

\section{Data availability}

The data that support the findings of this study are available from the corresponding author upon reasonable request. The source data underlying Fig. 2a and Supplementary Fig. $1 \mathrm{a}-\mathrm{j}$ are provided as a Source Data file.

\section{Code availability}

This study does not use custom computer code or algorithm to generate results that are reported in the paper and central to its main claims.

Received: 9 August 2019; Accepted: 13 February 2020;

Published online: 13 March 2020

\section{References}

1. Ghosh, I. et al. Organic semiconductor photocatalyst can bifunctionalize arenes and heteroarenes. Science 365, 360-366 (2019).

2. Pieber, B., Shalom, M., Antonietti, M., Seeberger, P. H. \& Gilmore, K. Continuous heterogeneous photocatalysis in serial micro-batch reactors. Angew. Chem. Int. Ed. 57, 9976-9979 (2018).

3. Kurpil, B., Otte, K., Antonietti, M. \& Savateev, A. Photooxidation of Nacylhydrazones to 1,3,4-oxadiazoles catalyzed by heterogeneous visible-lightactive carbon nitride semiconductor. Appl. Catal. B 228, 97-102 (2018).

4. Savateev, A., Ghosh, I., König, B. \& Antonietti, M. Photoredox catalytic organic transformations using heterogeneous carbon nitrides. Angew. Chem. Int. Ed. 57, 15936-15947 (2018).

5. Markushyna, Y., Smith, C. A. \& Savateev, A. Organic photocatalysis: carbon nitride semiconductors vs. molecular catalysts. Eur. J. Org. Chem. https://doi. org/10.1002/ejoc.201901112 (2019).

6. Cao, S., Low, J., Yu, J. \& Jaroniec, M. Polymeric photocatalysts based on graphitic carbon nitride. Adv. Mater. 27, 2150-2176 (2015).

7. Savateev, A. et al. Synthesis of an electronically modified carbon nitride from a processable semiconductor, 3-amino-1,2,4-triazole oligomer, via a topotacticlike phase transition. J. Mater. Chem. A 5, 8394-8401 (2017).

8. Kisch, H. Semiconductor photocatalysis-mechanistic and synthetic aspects. Angew. Chem. Int. Ed. Engl. 52, 812-847 (2013).

9. Stephenson, C., Yoon, T. \& MacMillan, D. W. C. Visible Light Photocatalysis in Organic Chemistry (Wiley, 2018).

10. Dvoranova, D., Barbierikova, Z. \& Brezova, V. Radical intermediates in photoinduced reactions on $\mathrm{TiO} 2$ (an EPR spin trapping study). Molecules 19, 17279-17304 (2014).

11. Nagib, D. A. \& Macmillan, D. W. C. Trifluoromethylation of arenes and heteroarenes by means of photoredox catalysis. Nature 480, 224-228 (2011).

12. Baar, M. \& Blechert, S. Graphitic carbon nitride polymer as a recyclable photoredox catalyst for fluoroalkylation of arenes. Chem. Eur. J. 21, 526-530 (2015).

13. Zhao, Y., Shalom, M. \& Antonietti, M. Visible light-driven graphitic carbon nitride (g-C3N4) photocatalyzed ketalization reaction in methanol with methylviologen as efficient electron mediator. Appl. Catal. B 207, 311-315 (2017).

14. Filler, R., Kobayashi, Y. \& Yagupolskii, L. Organofluorine Compounds in Medicinal Chemistry and Biomedical Applications (Elsevier Science LTD, 1993).

15. Zafrani, Y. et al. Difluoromethyl bioisostere: examining the "Lipophilic Hydrogen Bond Donor" concept. J. Med. Chem. 60, 797-804 (2017).

16. Mai, V. H. \& Nikonov, G. I. Hydrodefluorination of fluoroaromatics by isopropyl alcohol catalyzed by a ruthenium NHC complex. An unusual role of the carbene ligand. ACS Catal. 6, 7956-7961 (2016).
17. Waghmode, S. B., Mahale, G., Patil, V. P., Renalson, K. \& Singh, D. Efficient method for demethylation of aryl methyl ether using aliquat-336. Synth. Commun. 43, 3272-3280 (2013)

18. Rebacz, N. A. \& Savage, P. E. Anisole hydrolysis in high temperature water. Phys. Chem. Chem. Phys. 15, 3562-3569 (2013).

19. Zhang, J., Xing, C., Tiwari, B. \& Chi, Y. R. Catalytic activation of carbohydrates as formaldehyde equivalents for stetter reaction with enones. $J$. Am. Chem. Soc. 135, 8113-8116 (2013).

20. Kohls, P., Jadhav, D., Pandey, G. \& Reiser, O. Visible light photoredox catalysis: generation and addition of $\mathrm{N}$-aryltetrahydroisoquinoline-derived $\alpha$ amino radicals to michael acceptors. Org. Lett. 14, 672-675 (2012).

21. Ruiz Espelt, L., Wiensch, E. M. \& Yoon, T. P. Brønsted acid cocatalysts in photocatalytic radical addition of $\alpha$-amino $\mathrm{C}-\mathrm{H}$ bonds across michael acceptors. J. Org. Chem. 78, 4107-4114 (2013).

22. Ruiz Espelt, L., McPherson, I. S., Wiensch, E. M. \& Yoon, T. P. Enantioselective conjugate additions of $\alpha$-amino radicals via cooperative photoredox and Lewis acid catalysis. J. Am. Chem. Soc. 137, 2452-2455 (2015).

23. Murphy, J. J., Bastida, D., Paria, S., Fagnoni, M. \& Melchiorre, P. Asymmetric catalytic formation of quaternary carbons by iminium ion trapping of radicals. Nature 532, 218-222 (2016)

24. Savateev, A. \& Antonietti, M. Ionic carbon nitrides in solar hydrogen production and organic synthesis: exciting chemistry and economic advantages. ChemCatChem 11, 6166-6176 (2019).

25. Cui, Q. et al. Phenyl-modified carbon nitride quantum dots with distinct photoluminescence behavior. Angew. Chem. Int. Ed. 55, 3672-3676 (2016).

26. Kurpil, B. et al. Hexaazatriphenylene doped carbon nitrides-biomimetic photocatalyst with superior oxidation power. Appl. Catal. B 217, 622-628 (2017).

27. Kurpil, B., Markushyna, Y. \& Savateev, A. Visible-light-driven reductive (Cyclo)dimerization of chalcones over heterogeneous carbon nitride photocatalyst. ACS Catal. 9, 1531-1538 (2019).

28. Kurpil, B., Kumru, B., Heil, T., Antonietti, M. \& Savateev, A. Carbon nitride creates thioamides in high yields by the photocatalytic Kindler reaction. Green. Chem. 20, 838-842 (2018).

29. Savateev, A., Kurpil, B., Mishchenko, A., Zhang, G. \& Antonietti, M. A. "waiting" carbon nitride radical anion: a charge storage material and key intermediate in direct $\mathrm{C}-\mathrm{H}$ thiolation of methylarenes using elemental sulfur as the "S"-source. Chem. Sci. 9, 3584-3591 (2018).

30. Kurpil, B. et al. Carbon nitride photocatalyzes regioselective aminium radical addition to the carbonyl bond and yields $\mathrm{N}$-fused pyrroles. Nat. Commun. 10 945-945 (2019).

31. Markushyna, Y. et al. Halogenation of aromatic hydrocarbons by halide anion oxidation with poly(heptazine imide) photocatalyst. Appl. Catal. B 248, 211-217 (2019)

32. Ou, H., Tang, C., Chen, X., Zhou, M. \& Wang, X. Solvated electrons for photochemistry syntheses using conjugated carbon nitride polymers. ACS Catal. 9, 2949-2955 (2019).

33. Lau VWh et al. Dark photocatalysis: storage of solar energy in carbon nitride for time-delayed hydrogen generation. Angew. Chem. Int. Ed. 56, 510-514 (2017).

34. Plutschack, M. B., Pieber, B., Gilmore, K. \& Seeberger, P. H. The Hitchhiker's guide to flow chemistry. Chem. Rev. 117, 11796-11893 (2017).

35. Movsisyan, M. et al. Taming hazardous chemistry by continuous flow technology. Chem. Soc. Rev. 45, 4892-4928 (2016).

36. Woźnica, M., Chaoui, N., Taabache, S. \& Blechert, S. THF: an efficient electron donor in continuous flow radical cyclization photocatalyzed by graphitic carbon nitride. Chem. Eur. J. 20, 14624-14628 (2014).

37. Bajada M. et al. Visible light flow reactor packed with porous carbon nitride for aerobic substrate oxidations. ACS Appl. Mater. Interfaces https://doi.org/ 10.1021/acsami.9b19718 (2020).

38. Rodríguez, N. A., Savateev, A., Grela, M. A. \& Dontsova, D. Facile synthesis of potassium poly(heptazine imide) (PHIK)/Ti-based metal-organic framework (MIL-125-NH2) composites for photocatalytic applications. ACS Appl. Mater. Interfaces 9, 22941-22949 (2017).

39. Krivtsov, I. et al. Water-soluble polymeric carbon nitride colloidal nanoparticles for highly selective quasi-homogeneous photocatalysis. Angew. Chem. Int. Ed. 59, 487-495 (2020).

40. Jones, W. et al. A comparison of photocatalytic reforming reactions of methanol and triethanolamine with Pd supported on titania and graphitic carbon nitride. Appl. Catal. B 240, 373-379 (2019).

41. Zhang, G. et al. Electron deficient monomers that optimize nucleation and enhance the photocatalytic redox activity of carbon nitrides. Angew. Chem. Int. Ed. 58, 14950-14954 (2019).

42. Samanta, S., Khilari, S., Pradhan, D. \& Srivastava, R. An efficient, visible light driven, selective oxidation of aromatic alcohols and amines with $\mathrm{O} 2$ using BiVO4/g-C3N4 nanocomposite: a systematic and comprehensive study toward the development of a photocatalytic process. ACS Sustain. Chem. Eng. 5, 2562-2577 (2017). 
43. Chen, Z. et al. "The Easier the Better" preparation of efficient photocatalystsmetastable poly(heptazine imide) salts. Adv. Mater. 29, 1700555 (2017).

44. Maruoka, K., Shimada, I., Imoto, H. \& Yamamoto, H. Conjugate addition of reactive carbanions to $\alpha, \beta$-unsaturated ketones in the presence of ATPH. Synlett 1994, 519-520 (1994).

45. Serpone, N. Relative photonic efficiencies and quantum yields in heterogeneous photocatalysis. J. Photochem. Photobiol. A 104, 1-12 (1997).

46. Francesconi, I. et al. 2,4-Diphenyl furan diamidines as novel antiPneumocystis carinii pneumonia agents. J. Med. Chem. 42, 2260-2265 (1999).

47. Thompson, B. B. \& Montgomery, J. Enone-alkyne reductive coupling: a versatile entry to substituted pyrroles. Org. Lett. 13, 3289-3291 (2011).

48. Su, F. et al. Aerobic oxidative coupling of amines by carbon nitride photocatalysis with visible light. Angew. Chem. Int. Ed. Engl. 50, 657-660 (2011).

49. $\mathrm{Hu}, \mathrm{X}$. Q. et al. Catalytic N-radical cascade reaction of hydrazones by oxidative deprotonation electron transfer and TEMPO mediation. Nat. Commun. 7, 11188 (2016).

\section{Acknowledgements}

We gratefully acknowledge the Max-Planck Society for generous financial support. The Deutsche Forschungsgemeinschaft is gratefully acknowledged for providing financial support for this project (DFG-An 156 13-1). B.P. acknowledges financial support by a Liebig Fellowship of the German Chemical Industry Fund (Fonds der Chemischen Industrie, FCI). The authors thank Olaf Niemeyer (the head of NMR facility of the MPICI), Michael Born (assembly of LED), Marco Bott (fabrication of the steel cylinder for light source) for technical and scientific support.

\section{Author contributions}

S.M. synthesis of precursors, photocatalytic tests, chemical properties of $\gamma, \gamma$-dichloroketones, flow photoreactor, preparation of manuscript and ESI; B.K. synthesis of precursors, photocatalytic tests; B.P. flow photoreactor; M.A. planning of research work; A.S. planning of research work, preparation of manuscript and ESI.

\section{Competing interests}

The authors declare no competing interests.

\section{Additional information}

Supplementary information is available for this paper at https://doi.org/10.1038/s41467020-15131-0.

Correspondence and requests for materials should be addressed to A.S

Peer review information Nature Communications thanks the anonymous reviewer(s) for their contribution to the peer review of this work. Peer reviewer reports are available.

Reprints and permission information is available at http://www.nature.com/reprints

Publisher's note Springer Nature remains neutral with regard to jurisdictional claims in published maps and institutional affiliations.

(c) (i) Open Access This article is licensed under a Creative Commons Attribution 4.0 International License, which permits use, sharing, adaptation, distribution and reproduction in any medium or format, as long as you give appropriate credit to the original author(s) and the source, provide a link to the Creative Commons license, and indicate if changes were made. The images or other third party material in this article are included in the article's Creative Commons license, unless indicated otherwise in a credit line to the material. If material is not included in the article's Creative Commons license and your intended use is not permitted by statutory regulation or exceeds the permitted use, you will need to obtain permission directly from the copyright holder. To view a copy of this license, visit http://creativecommons.org/ licenses/by/4.0/.

(C) The Author(s) 2020 